ISSN: $1130-3743$ - e-ISSN: 2386-5660

DOI: http://dx.doi.org/10.14201/teoredu2017291161187

\title{
LA SOSTENIBILIDAD EN LOS GRADOS \\ UNIVERSITARIOS: PRESENCIA Y COHERENCIA
}

\author{
Sustainability in university degrees: \\ presence and coherence
}

\section{Durabilité dans les degrés universitaires: présence et cobérence}

\author{
María José BAuTISTA-CERRO Ruiz* y María José DíAz GONZÁLEZ*** \\ * Universidad Nacional de Educación a Distancia. Facultad de Educación. \\ Departamento de Teoría de la Educación y Pedagogía Social. \\ C/Juan del Rosal, 14.28040 Madrid.mjbautistac@edu.uned.es \\ * Consejería de Educación. Comunidad de Madrid.mjdiazgonzalez@gmail.com
}

Fecha de recepción: enero de 2017

Fecha de aceptación: marzo de 2017

RESUMEN

Nos encontramos ante una crisis socioambiental sin precedentes y en un contexto de incertidumbre que dificulta su gestión. Para enfrentarnos a esta situación se requieren profesionales con una sólida formación que puedan tomar decisiones con criterios de sostenibilidad. Esta necesidad es recogida desde la educación superior y planteada como un desafío para las titulaciones de Grado. El objetivo de este trabajo es conocer si se ha concretado una inclusión de elementos de sostenibilidad en las nuevas titulaciones de Grado de la UNED. Para ello, se plantea el análisis de contenido de sus memorias de grado $(n=26)$ realizando un tratamiento cualitativo y cuantitativo de la información con el software Atlas.ti. Se realiza un análisis que permite conocer la presencia de la sostenibilidad en las titulaciones y valorar la coherencia de Grados en torno a este tema.

Palabras clave: sostenibilidad curricular; universidad; competencias. 


\section{SUMMARY}

We are faced an unprecedented socio-environmental crisis and in a context of uncertainty that makes management difficult. In order to deal with this situation, we need professionals with a firm training who can make decisions with sustainability criteria. This need is collected from higher education and posed as a key challenge for university degrees. The objective of this work is to know if the elements of sustainability have been included in the new degree programs of the UNED. In order to do so, the content analysis of its degree reports $(n=26)$ is proposed, making a qualitative and quantitative treatment of the information with Atlas.ti software. An analysis is made to know the presence of the sustainability in the degree programmes and to evaluate his coherence around this subject.

Key words: curricular sustainability; university; competencies.

\section{SOMMAIRE}

Nous sommes confrontés à une crise socio-environnemental sans précédent dans un contexte d'incertitude qui rend la gestion difficile. Les professionnels doivent posséder une solide formation pour prendre des décisions avec critères de durabilité. Ce besoin est recunue par l'enseignement supérieur et posé comme un défi pour les grades universitaires. L'objectif de ce travail est de savoir si l'inclusion d'éléments de la durabilité dans les degrés de UNED est matérialisé. Pour ce faire, l'analyse du contenu de ses rapports d'études $(n=26)$ est proposé, ce qui rend un traitement qualitatif et quantitatif de l'information avec le logiciel Atlas.ti. L'analyse permet de connaître la présence de la durabilité dans les programmes universitaires et d'évaluer leur cohérence.

Mots clés: durabilité dans le curriculum; université; compétences.

\section{INTRODUCCIÓN}

En la actualidad nos encontramos inmersos en una crisis ambiental de grandes proporciones y cuyas consecuencias podemos advertir tanto a nivel ecológico (cambio climático, deterioro de ecosistemas, contaminación, etc.) como social (desigualdad, pobreza, exclusión, etc.) (Novo, 2009; Aznar y Ull, 2013; IPCC, 2013; DESA, 2016). Los desafíos de los profesionales del siglo XXI pasan por enfrentar con éxito situaciones nuevas cuya gestión se plantea a diferentes escalas (global-local) y en entornos de incertidumbre. Ante una crisis de carácter sistémico, dichos profesionales deben contar con una sólida formación específica, con una base científica y ética que les facilite la introducción de criterios de sostenibilidad en su toma de decisiones.

En la profunda reforma que, con motivo del proceso de Bolonia ha experimentado la universidad, la necesidad de recoger estos desafíos no ha sido pasada 
por alto. Esta cuestión se refleja en la Ley Orgánica 4/2007 de Universidades que se desarrolla en el Real Decreto 1393/2007, por el que se establece la ordenación de las enseñanzas universitarias oficiales. En el preámbulo del R. D. se especifica que

se debe tener en cuenta que la formación en cualquier actividad profesional debe contribuir al conocimiento y desarrollo de los Derechos Humanos, los principios democráticos, los principios de igualdad entre mujeres y hombres, de solidaridad, de protección medioambiental, de accesibilidad universal y diseño para todos, y de fomento de la cultura de la paz.

Todos los elementos aquí señalados son requisitos del desarrollo sostenible y aparecen igualmente en la Agenda 2030 para el Desarrollo Sostenible (ONU, 2015). Si atendemos a lo que está pasando en la educación superior es necesario comprobar si la perspectiva de la sostenibilidad ya se encuentra presente en la formación de sus estudiantes. Para ello, hemos planteado un estudio de caso que nos ha permitido valorar si la universidad está formando a sus egresados en competencias que les ayuden a integrar la sostenibilidad como un criterio necesario en su toma de decisiones profesional y personal. La investigación se diseñó con el objetivo de contribuir a la inclusión de la sostenibilidad en los Grados universitarios. Para ello entendíamos como necesario conocer la presencia efectiva de la misma en el diseño de los programas universitarios y establecer un mapa de referencias en los mismos, detectando las virtudes y carencias en este campo.

\section{ANTECEDENTES Y FUNDAMENTACIÓN}

La crisis actual, de una gran complejidad, tiene en su base la manera en la que los seres humanos nos relacionamos con el medio natural y también con otros grupos humanos. La crisis, o las diversas crisis entretejidas, no suceden de manera aislada sino en esferas de límites difusos cuyos elementos están recíprocamente interrelacionados, de manera que se realimentan, crean sinergias y emergencias nuevas imposibles de tratar de manera aislada. "Descartadas las hipótesis simplificadoras sobre el calado del cambio que afrontamos, el alumbramiento y la concreción práctica de los nuevos paradigmas éticos y sociales que permitan un cambio de época deseable solo pueden interpretarse como un proceso de extraordinaria lucidez y complejidad" (Prats, 2016, 32). Frente a este desafío coincidimos con Novo cuando afirma: "Si la esencia de la vida en comunidad se basa en la posibilidad de elucidar e integrar los mejores rasgos de los individuos que la constituyen, es necesario que la educación, como instrumento de socialización y de actitud crítica, adopte respuestas válidas para los retos que tiene planteados la humanidad» (2009, 197), especialmente en este contexto de crisis.

La educación y la formación de las nuevas generaciones se presentan como una herramienta imprescindible para mejorar la gestión de los problemas socioambientales. Este aspecto viene recogido desde las primeras cumbres internacionales celebradas sobre esta temática (Conferencia de Naciones Unidas sobre Medio 
Ambiente en Estocolmo, 1972; Conferencia de Naciones Unidas de Medio Ambiente y Desarrollo en Río de Janeiro, 1992, etc.). En esta línea, las instituciones internacionales llevan décadas señalando a la Universidad como escenario principal en los procesos de capacitación hacia la sostenibilidad (Ull, Martínez Agut, Piñero y Aznar Minguet, 2010; Tilbury, 2011; UESD, 2015). La aprobación de la Década de la Educación para el Desarrollo Sostenible (2005-2014) por Naciones Unidas ha sido un paso significativo que sitúa la educación en el centro del proceso para avanzar hacia la sostenibilidad y, también, como llamada de atención a las instituciones educativas sobre su papel protagónico. En la Agenda 2030 aparece la educación a lo largo de todo el documento como condición necesaria para alcanzar los objetivos de desarrollo sostenible (ODS), pero es especialmente relevante el objetivo 4, específico sobre educación, donde se puede leer:

Garantizar que todos los alumnos adquieran los conocimientos teóricos y prácticos necesarios para promover el desarrollo sostenible, entre otras cosas mediante la educación para el desarrollo sostenible y la adopción de estilos de vida sostenibles, los derechos humanos, la igualdad entre los géneros, la promoción de una cultura de paz y no violencia, la ciudadanía mundial y la valoración de la diversidad cultural y de la contribución de la cultura al desarrollo sostenible, entre otros medios (ONU, 2015, 20).

Las universidades españolas no se han mantenido ajenas a estas demandas, al menos así se desprende del trabajo de Barañano (2012, 34):

Cabe afirmar que las universidades españolas entienden mayoritariamente su compromiso con la RS (responsabilidad social) y con el Ds (desarrollo sostenible) en el marco de una nueva concepción de la universidad, y como una re-conceptualización de esta institución y de su función. El aspecto más destacado de esta nueva concepción es la importancia del retorno a la sociedad, que ahora se pone, de manera explícita, en el corazón de su misión y de su identidad.

Por todo ello, parece imprescindible seguir avanzando en este compromiso y apostar por la formación que contenga competencias en sostenibilidad. Como señala Murga-Menoyo (2015), dichas competencias resultan indispensables para cada ciudadano ya que contribuyen a modificar los patrones y modos de vida, a la vez que se favorecen los cambios en el modelo económico de producción y consumo.

\subsection{Las competencias en sostenibilidad como propuesta y respuesta}

La introducción de competencias en sostenibilidad en la educación superior es una línea de trabajo abierta desde hace décadas por un amplio elenco de universidades y grupos de investigación a nivel nacional e internacional. Entre las iniciativas internacionales más importantes debemos destacar el Programa de Educación para el Desarrollo Sostenible (ESD Programme) de la UNESCO o la Universidad de la Naciones Unidas (UNU). Así mismo, es necesario mencionar las cinco grandes 
redes que trabajan en la educación superior: la University Leaders for Sustainable Future (ULSF), la Association of Universities (IAU), la Co-operation Program in Europe for Research on Nature and Industry throug Coordinated University Studies (COPERNICUS) y la Global Higher Education for Sustainability Partnership (GHESP), que agrupa, a su vez a IAU, ULSF, COPERNICUS-Campus y unU. Todas ellas con importantes aportaciones desde su creación.

En la Unión Europea existen distintas líneas de trabajo. La Estrategia para el Desarrollo Sostenible afirma que "la sociedad del conocimiento debe impulsar el desarrollo sostenible. Ha de hacerse especial hincapié en el ámbito de la educación y la formación del mayor número posible de ciudadanos, a fin de estimular un cambio de comportamiento y proporcionarles las competencias necesarias para alcanzar los objetivos fijados en la estrategia» (Unión Europea, s. f.). Tomando este testigo es interesante mencionar los importantes esfuerzos realizados por países como Suecia, Inglaterra u Holanda ${ }^{1}$. Recientemente se ha presentado el plan estratégico sobre desarrollo sostenible que recoge los desafíos de la Agenda 2030 de las Naciones Unidas para el Desarrollo Sostenible y esboza la forma en que la UE alcanzará los objetivos de desarrollo sostenible (ODS) en el futuro (Comisión Europea, 2016).

En nuestro país contamos con la Red ACES (Red de Ambientalización Curricular de los Estudios Superiores) y la Red EDusost, que reúne a las universidades catalanas. Especial relevancia tiene la Comisión Sectorial Sostenibilidad (antes conocida como CADEP-Comisión Sectorial de Calidad Ambiental Desarrollo Sostenible y Prevención de Riesgos) de la Conferencia de Rectores de Universidades Españolas (CRUE). Constituido en el 2009, este grupo de trabajo tiene como objetivo, entre otros, la inclusión de criterios y competencias para la Sostenibilidad en todos los planes de estudio universitarios (Barrón, Navarrete y Ferrer-Balas, 2010).

La Asamblea General CRUE aprobó en marzo de 2005 las Directrices para la introducción de la sostenibilidad en los currícula ${ }^{2}$ y, entre las conclusiones presentadas, cabe destacar la necesidad de promover la inclusión de la sostenibilidad en todos los planes de estudio; la investigación en educación para la sostenibilidad; las acciones de formación del profesorado para la inclusión de contenidos sobre sostenibilidad en sus asignaturas, y elaboración de recursos y materiales de apoyo a la introducción de la sostenibilidad en el currículum académico.

Existen múltiples propuestas y modelos que intentan definir y enunciar las competencias para el desarrollo sostenible. Coincidimos con la propuesta de MurgaMenoyo $(2015,77)$ que defiende que "no se trata tanto de "ampliar" contenidos

1. En Suecia, desde 2006 todas las instituciones de educación superior deben promover el desarrollo sostenible en sus actividades. En Holanda cuentan con la Red Nacional Holandesa para la introducción del desarrollo sostenible en los planes de estudio de educación superior (DHO), creada en 1998. En Reino Unido la Higher Education Funding Council for England (HEFCE) está formada por 130 instituciones de educación superior y 124 colleges.

2. El documento experimentó posteriores revisiones, aprobadas por CADEP en 2012, y fue presentado en la Asamblea General de la CRUE de 28 de junio de 2012 en la Universitat de Girona. 
de aprendizaje cuanto de "repensar", "integrar" y "transformar" la docencia orientándola hacia la sostenibilidad". Como vemos en la Tabla 1, autores con amplia trayectoria en el enfoque de la sostenibilidad presentan una coincidencia con las competencias enunciadas por UNESCO ya que éstas establecen unas competencias amplias que bien podrían ser consideradas áreas competenciales, y, tomando aquellas como referencia, presentan sus propuestas.

TABLA 1

REVISIÓN DE LAS PRINCIPALES COMPETENCIAS EN SOSTENIBILIDAD RECOGIDAS POR MODELOS Y AUTORES

\begin{tabular}{|c|c|c|c|c|c|c|c|}
\hline $\begin{array}{c}\text { COMPETENCIAS } \\
\text { EN } \\
\text { SOSTENIBILIDAD } \\
\text { UNESCO }\end{array}$ & CRUE & $\begin{array}{c}\text { DE } \\
\text { HAAN } \\
(2010)\end{array}$ & $\begin{array}{c}\text { ULL } \\
\text { ET } A L . \\
(2010)\end{array}$ & $\begin{array}{c}\text { WIEK, } \\
\text { WITHYCOMBE } \\
\text { Y REDMAN } \\
(2011)\end{array}$ & $\begin{array}{c}\text { AlBAREDA- } \\
\text { TIANA Y } \\
(2012)\end{array}$ & $\begin{array}{c}\text { GONZALVO- } \\
\text { CIRAC } \\
(2013)\end{array}$ & $\begin{array}{c}\text { MURGA- } \\
\text { (2015) }\end{array}$ \\
\hline Análisis crítico & $\mathrm{x}$ & & $\mathrm{x}$ & $\mathrm{x}$ & $\mathrm{x}$ & $\mathrm{x}$ & $\mathrm{x}$ \\
\hline $\begin{array}{c}\text { Reflexión } \\
\text { sistémica }\end{array}$ & $\mathrm{x}$ & $\mathrm{x}$ & $\mathrm{x}$ & $\mathrm{x}$ & $\mathrm{x}$ & $\mathrm{x}$ \\
\hline $\begin{array}{c}\text { Toma de } \\
\text { decisiones } \\
\text { colaborativa }\end{array}$ & $\mathrm{x}$ & $\mathrm{x}$ & $\mathrm{x}$ & $\mathrm{x}$ & $\mathrm{x}$ & $\mathrm{x}$ & $\mathrm{x}$ \\
\hline $\begin{array}{c}\text { Sentido de la } \\
\text { responsabilidad } \\
\text { hacia las } \\
\text { generaciones } \\
\text { presentes } \\
\text { futuras }\end{array}$ & $\mathrm{x}$ & $\mathrm{x}$ & $\mathrm{x}$ & $\mathrm{x}$ & $\mathrm{x}$ & $\mathrm{x}$ & $\mathrm{x}$ \\
\hline
\end{tabular}

Además de la bibliografía que trabaja específicamente sobre el establecimiento de las competencias en sostenibilidad, existen varias recomendaciones de instituciones nacionales como la CRUE (CADEP-CRUE, 2011a) o internacionales como la Copernicus Alliance (UE4SD, 2015) sobre la necesidad de evaluar si se están incluyendo dichas competencias en los nuevos Grados universitarios. Esta necesidad también ha sido recogida por distintos equipos de investigación (Junyent y Geli, 2008; Alvareda-Tiana y Gonzalvo-Cirac, 2013; Aznar et al., 2016; Bautista-Cerro, 2014). Además, encontramos la necesidad de trabajar de forma interdisciplinar y transdisciplinar (Tilbury, 2011; Barth, Godemann, Rieckmann y Stoltenberg, 2007), considerar diferentes escalas temporales (De Kraker, Cörvers, Ivens, Lansu y Van Dam-Mieras, 2007) o integrar simultáneamente las capacidades cognitivas (cabeza), operativas (manos) y afectivas (corazón) (Sipos, Battisti y Grimm, 2008). 


\subsection{Competencias en sostenibilidady empleabilidad. Ventaja individualy beneficio social}

No es la primera vez que se plantea que la Universidad debe protagonizar cambios para responder a las necesidades de la sociedad. Ahora bien, estos cambios, esta evolución, deben centrarse en las funciones de la educación superior que se sustantivan, como señala Medina $(2005,17)$ en «una relación positiva de correspondencia de una Institución con las concretas necesidades del organismo social de su entorno. La función, por eso, no es atemporal; no es neutra, sino histórica e interesada. Fruto de unas estructuras y necesidades sociales determinadas, sirve de refuerzo eficaz de las mismas». Y estas necesidades están relacionadas con los numerosos retos que tienen planteados, retos que tienen una característica común: su complejidad. Por lo tanto, se trata de que la función de la universidad asuma y sea capaz de responder a las necesidades de la sociedad en la que está inserta.

Sin embargo, la universidad también debe estar atenta a la deriva de los últimos años, pues, como señala García-Gutiérrez (2014, 107), «se encuentra ante la espada de una formación socio-económicamente útil, y la pared de aquello que aún continúa dando sentido a su denominación de "superior". Es urgente reflexionar y trasladar también el debate a los propios estudiantes sobre lo que está en juego: los valores del mercado y de la economía (tal y como se piensa mayoritariamente), o si aun seguimos creyendo en la política y nuestra responsabilidad sobre generaciones futuras» $\mathrm{y}$, añadiríamos, presentes.

Esta deriva no proviene solo del mercado, instituciones como el Consejo Europeo se hacen eco de ella con afirmaciones como la siguiente: «La educación y la formación son requisitos previos para que funcione bien el "triángulo del conocimiento" (educación-investigación-innovación) y desempeñan un papel capital en la promoción del crecimiento y del empleo" (Consejo Europeo, 9 de marzo de 2007. Conclusiones de la Presidencia, 6). Cuestiones que encauzan la educación y la formación hacia las necesidades de crecimiento y empleo (la primera muy discutida desde la perspectiva de la sostenibilidad y la segunda matizable).

Es cierto que hay una fundada preocupación sobre las tasas de desempleo en toda Europa y especialmente en España. Resulta muy fácil, ante esta situación, encontrar afirmaciones sobre la responsabilidad de las universidades en la formación de trabajadores (Martín del Peso, Rabadán y Hernández, 2013) y de la defensa de la empleabilidad como un factor determinante de la pertinencia o de la calidad de un programa educativo (Rodríguez, Prades, Bernáldez y Sánchez, 2010).

Se espera que la educación provea a los estudiantes de una formación que les facilite su integración en el mercado laboral. En momentos de crisis la empleabilidad se ha convertido en palabra fetiche para el diseño de los Grados y por lo tanto uno de los objetivos de la formación. Algunos autores (Boltansky y Chiapello, 2002) definen la empleabilidad centrada en el individuo, otros incluyen aspectos relacionados con el contexto (Thijssen, Van der Heijden y Rocco, 2008). En nuestro caso, entendemos con Yorke (2004) que la empleabilidad la constituyen un 
conjunto de logros, habilidades, conocimientos y atributos personales que aumentan la probabilidad de los graduados de encontrar un empleo y de tener éxito en sus puestos. Este éxito supone un beneficio para el propio individuo, pero también para la empresa, para la propia comunidad y para la economía en su conjunto. Esta visión presenta tres perspectivas que son complementarias (Bautista-Cerro, 2014):

- Personal. El individuo alcanza el trabajo deseado y para el que ha sido formado. Supone una ganancia personal ya que el individuo consigue cubrir sus aspiraciones. Por otro lado, a través de su actividad profesional consigue una contraprestación económica que le permite acceder a bienes y servicios.

- Empresarial. La empresa se beneficia de la realización profesional de los individuos que emplea. Este beneficio será mayor cuanto mejor formados se encuentren los egresados y mayor sea su capacidad para desarrollar y mejorar en su propio desempeño.

- Social. La empresa provee de bienes y servicios a la comunidad o a otras empresas. Si esta actividad se realiza de manera responsable, los beneficios de la comunidad son múltiples. Nos referimos a la producción de bienes y servicios que son demandados, en condiciones justas para sus trabajadores, minimizando riesgos laborales y ecológicos. Esta vertiente del beneficio solo es posible cuando todos los profesionales de la organización cuentan con los recursos necesarios para ello. Es decir, han integrado la vertiente de la sostenibilidad en su toma de decisiones y en la ejecución de su actividad.

La Universidad debe ser capaz de asumir esta perspectiva amplia, mucho más acorde con su misión. Desde ella, el individuo debe estar en posesión de una formación lo más completa posible que le permita tener una visión compleja de su trabajo y de las repercusiones de sus decisiones a corto, medio y largo plazo. Así mismo debe ser consciente de los desafíos presentes en las sociedades y de las posibilidades de acercarse a ellos a través del desempeño de su profesión. Hablamos, por tanto, de una serie de competencias complejas que deben responder a los desafíos de nuestras sociedades, donde sin duda el desafío ambiental es el más urgente de todos.

No se trata, por tanto, de que las universidades se centren en la creación de programas de estudios para formar profesionales en las nuevas ocupaciones de un mercado que encuentra en la sostenibilidad una opción de negocio (es el caso de las energías renovables y la recuperación de residuos, entre otros). El PNUMA afirma que "El concepto de "economía verde" no sustituye al de "desarrollo sostenible" [...] la sostenibilidad sigue siendo un objetivo vital a largo plazo, y para alcanzarlo es necesario enverdecer la economía” (PNUMA, 2011, 9). El trabajo debe orientarse hacia la creación de nuevo conocimiento y su contribución al desarrollo adecuado de competencias en torno al desarrollo sostenible (Rieckman, 2012; Murga-Menoyo, 2014). La Universidad debe facilitar la adquisición de ese conocimiento, en todos 
los programas, para que los profesionales integren en su quehacer profesional esta dimensión como un elemento clave en todas sus decisiones.

\subsection{El diseño de los Grados, no todo está en las competencias}

La inclusión de competencias en sostenibilidad es un requisito importante para entender que un Grado contribuye a formar profesionales con la perspectiva del desarrollo sostenible. Sin embargo, la novedad del concepto y su desconocimiento entre buena parte del profesorado no ha facilitado la inserción de este tipo de competencias en el diseño de los planes de estudio. Ello no significa que la perspectiva del desarrollo sostenible y los valores a él asociados no se encuentren implícitos en los proyectos docentes de las titulaciones.

En las memorias de verificación se encuentran los elementos que definen cada Título, desde la justificación de su necesidad, los objetivos que persigue, las competencias que trata de alcanzar, y también su desarrollo en materias, resultados de aprendizaje y asignaturas. Lo deseable sería que las referencias a la sostenibilidad estuvieran presentes a lo largo de toda la memoria y no solo expresadas en forma de competencias, aunque las competencias sean el elemento central en el diseño de los Grados.

Por otro lado, si observamos el repaso realizado sobre competencias, anteriormente aportado, parece existir cierta tendencia a plantear las competencias en sostenibilidad como competencias genéricas, es decir, aquellas que todos los estudiantes deben alcanzar en el mayor grado posible, sea cual sea su área de estudio, tales como pensamiento sistémico, pensamiento crítico, toma de decisiones colaborativa, etc. Pero estas competencias son muy amplias y su mera inclusión en la memoria de verificación de un Grado entendemos que no implica necesariamente un trabajo desde el marco de la sostenibilidad. Ante las competencias así enunciadas no es posible afirmar categóricamente que colaboran a la formación en temas de sostenibilidad y es necesario abrir el foco del análisis. A este respecto, los objetivos de desarrollo sostenible (ODS) enunciados por Naciones Unidas, y ya mencionados, presentan un amplio abanico de campos, consensuados por la comunidad científica, donde es necesario trabajar para avanzar hacia la sostenibilidad. Coincidimos con Aznar, Ull, Martínez-Agut y Piñero, cuando afirman que «el desarrollo de competencias relacionadas con sus valores (del desarrollo sostenible) tiene que incluir las diversas acepciones desde las cuales se la define, así como integrar las variables que la conforman; y dada la cantidad y variedad de variables y sub-variables que la relacionan, su evaluación reviste una notable complejidad” $(2013,2)$. Por ello es necesario utilizar un instrumento para evaluar la presencia de la sostenibilidad en las titulaciones que nos permita rastrear esta dimensión en relación a sus valores, temáticas, planos, vertientes, núcleos, etc. Es decir, la efectiva presencia de una voluntad formativa en torno a la sostenibilidad plasmada en el diseño definitivo de cada Grado. 


\section{METODOlOGía}

\subsection{Objetivo del estudio}

El estudio que presentamos se diseñó con el objetivo general de contribuir a la inclusión de la sostenibilidad en los estudios de Grado de la UNED. Para ello entendíamos que era necesario realizar un análisis de los Grados en profundidad para conocer la presencia de la sostenibilidad, siendo este el primer objetivo al que nos enfrentamos. En segundo lugar, nos planteábamos establecer un mapa de referencias y competencias en sostenibilidad en los planes de estudio, detectando las virtudes y carencias internas de cada memoria y, en su conjunto, respecto de cada dimensión de la sostenibilidad (ambiental, sociocultural y económica). Todo ello nos permite valorar si la universidad se propone formar a sus egresados en competencias que les ayuden a integrar la sostenibilidad como un criterio necesario en su toma de decisiones profesional y personal y presentar las bases para el diseño de propuestas de mejora.

\subsection{Diseño metodológico}

La institución elegida para el estudio de caso es la UNED, universidad que con más de 200.000 estudiantes es la mayor universidad de España y una de las más grandes de Europa. No es ajena al compromiso con la sostenibilidad, prueba de ello es su reciente adhesión a la Carta de la Tierra, texto reconocido por la ONU como referente de la educación para el desarrollo sostenible. Su incidencia en la formación de profesionales es muy elevada y por tanto está justificada la necesidad de valorar si la sostenibilidad ha sido considerada en el diseño de los Grados universitarios, más allá de las asignaturas, cursos o postgrados específicos.

La metodología utilizada es de tipo descriptivo, empírico y ex post facto, adecuada para el análisis documental de las memorias de verificación de los Grados de la UNED $(n=26 \text { memorias })^{3}$. Estos documentos, elaborados por las propias facultades, cuentan con toda la información referida al diseño de cada titulación, siguiendo las indicaciones de la ANECA.

Para conocer en profundidad un Grado no es suficiente con conocer las referencias explícitas que aparecen en su diseño respecto a la sostenibilidad. La revisión integral de las memorias de verificación de los Grados desde la perspectiva del desarrollo sostenible implica que se deben encontrar referencias al mismo, en cualquiera de sus aspectos, en todos los epígrafes de las mismas. Para ello, no solo se estableció una estrategia de análisis de contenido desde el punto de vista semántico. Al buscar la coherencia interna de las memorias, era muy importante situar contextualmente

3. En el momento en el que se inició la recogida de la documentación, una memoria no se encontraba disponible. Esta memoria se hizo pública con posterioridad, pero el análisis ya había sido realizado. 
las citas. De esta manera era posible comprobar si las intenciones expresadas en los objetivos quedaban recogidas en forma de competencias y si estas tenían un reflejo entre los resultados de aprendizaje señalados para los estudiantes.

Se estableció una estrategia doble de codificación, por un lado, se establecieron como citas contextuales las siguientes: descripción, objetivos, competencias, resultados de aprendizaje y materias. De manera paralela se ha utilizado un instrumento elaborado por el Grupo de investigación ACUVEG de la Universidad de Valencia y previamente testado en diferentes investigaciones (Aznar Minguet et al., 2013; Aznar Minguet, Ull, Piñero y Martínez-Agut, 2016). Se trata de un tesauro que permite la recogida de datos mediante la verificación de la presencia de indicadores o categorías de análisis. Estas categorías fueron diseñadas por los autores a partir de los temas prioritarios contenidos en la Declaración de la Década de la Educación para el Desarrollo Sostenible de Naciones Unidas (2005-2014).

Las citas extraídas de las memorias se encuentran clasificadas atendiendo a las perspectivas social-cultural, económica y ecológica, y una centrada en la sostenibilidad en sentido amplio. El instrumento cuenta, por tanto, con cuatro categorías o familias y estas, a su vez, incluyen distintas subcategorías.

TABLA 2

Tesauro diseñado por El Grupo de InVESTigación aCuVEG DE la Universidad de Valencia (AZnar ET AL., 2013)

\begin{tabular}{|c|c|}
\hline CATEGORÍAS & \multicolumn{1}{c|}{ SubCATEGORÍAs DE Códigos } \\
\hline \multirow{3}{*}{ SOSTENB } & $\begin{array}{l}\text { Se asigna cuando en el apartado analizado encontramos la palabra } \\
\text { sostenibilidad o derivados (sostenible, sostenibles, insostenible, } \\
\text { sustentable, etc.). Se utiliza fundamentalmente para saber el número } \\
\text { de grados que contienen esta palabra o para centrarse en apartados } \\
\text { concretos que hacen uso de ella. }\end{array}$ \\
\hline \multirow{5}{*}{ SOCIOCLT } & $\begin{array}{l}\text { Hace referencia a la perspectiva sociocultural de la Década para el } \\
\text { Desarrollo Sostenible 2005-2014 e incluye: } \\
\text { DERHum: derechos humanos de las tres generaciones: a) democráticos, } \\
\text { civiles y políticos; b) económicos, sociales y culturales; c) de } \\
\text { solidaridad. } \\
\text { DIVCUL: diversidad y multiculturalidad, paz y seguridad humana. }\end{array}$ \\
\hline
\end{tabular}




\begin{tabular}{|c|c|}
\hline CATEGORÍAS & SuBCATEGORÍAS DE CÓDIGOS \\
\hline SOCIOCLT & $\begin{array}{l}\text { IGUAN: igualdad de géneros. No discriminación por razón de género, } \\
\text { defensa de los derechos de las mujeres. } \\
\text { SALD: promoción de la salud. Factores que determinan niveles } \\
\text { saludables de vida. } \\
\text { GOBR: gobernanza. Democratización social: transparencia, debates } \\
\text { libres, libertad de opinión, participación ciudadana. } \\
\text { DEMG: demografía. Cambios, situación, etc. } \\
\text { TICS: acceso a TICs. Generalización del uso; romper la brecha digital. } \\
\text { ETICN: responsabilidad ética, principios éticos, valores. }\end{array}$ \\
\hline AMBIN & $\begin{array}{l}\text { Hace referencia a los temas de la perspectiva medioambiental de la } \\
\text { Década para el Desarrollo Sostenible 2005-2014 e incluye: } \\
\text { RECURNA: Recursos naturales: protección y uso sostenible de los } \\
\text { recursos naturales indispensables para la vida. } \\
\text { BIODV: biodiversidad. } \\
\text { CNSE: conservación del medio natural. } \\
\text { CLIMN: cambio climático. } \\
\text { RURL: transformación rural. } \\
\text { URBN: urbanismo sostenible. } \\
\text { PROAM: problemática ambiental global, regional y local. Prevención } \\
\text { y mitigación de catástrofes. } \\
\text { INFHU: influencia e intervención humana en el medio ambiente. } \\
\text { ERENO: uso de energías renovables y eficiencia energética. }\end{array}$ \\
\hline ECONM & $\begin{array}{l}\text { Hace referencia a la perspectiva económica de la Década para el } \\
\text { Desarrollo Sostenible 2005-2014 e incluye: } \\
\text { POBREN: reducción de la pobreza. Implementación del nivel de } \\
\text { formación. } \\
\text { PROCON: producción y consumo responsables. Efectos sociales y } \\
\text { medioambientales de los hábitos de consumo. } \\
\text { MRC: economía de mercado. Armonizar las necesidades del mercado } \\
\text { con la protección ambiental y el objetivo de la equidad social. } \\
\text { RESPN: responsabilidad social de las empresas. Extensión de la RSC y } \\
\text { formación en competencias para la sostenibilidad. } \\
\text { IMPCT: valorar el impacto ambiental y social de las actividades } \\
\text { económicas. } \\
\text { GESTAM: gestión ambiental, repercusiones económicas de la gestión } \\
\text { ambiental. }\end{array}$ \\
\hline
\end{tabular}

La revisión de los textos se realizó a través de codificaciones por pares (ambos miembros del grupo de investigación) para comprobar la coincidencia o no de criterios. Se trata de un proceso complejo ya que parte del mismo requiere un consenso previo sobre el propio concepto de sostenibilidad y de los elementos a él asociados. Este trabajo se realizó tomando como centro del debate el tesauro 
y las citas de las memorias que resultaban especialmente problemáticas. Una vez que se dio por terminado el proceso de codificación de los documentos se inició el proceso de análisis de los resultados obtenidos a través de las herramientas del programa Atlas-ti y se complementó con las posibilidades de trabajo que ofrece la hoja de cálculo Excel.

\section{Resultados}

\subsection{La sostenibilidad en los Grados}

Si tenemos en cuenta las memorias en su conjunto, las menciones literales a la sostenibilidad o al desarrollo sostenible son muy escasas. En 16 de las memorias analizadas no se hace ninguna referencia explícita, en 8 de ellas encontramos entre 2 y 5 referencias, y solamente en 2 Grados encontramos repetidas alusiones a la sostenibilidad a lo largo del documento. Se trata de los Grados en Ciencias Ambientales y Turismo, cuyas memorias, además, desde las primeras páginas hacen alusión a la sostenibilidad.

De forma general, la presencia de otras categorías con referencias a elementos relacionados con la sostenibilidad (familia de categorías "SOCIOCLT", "AMBIN" y "ECONM») es escasa y se encuentra difuminada en los distintos Grados analizados. Esto avala la idea de que la sostenibilidad, con algunas excepciones, no formaba parte de las prioridades de quienes diseñaron los Títulos.

A continuación, se presenta un análisis detallado de las memorias que ha permitido apreciar que la presencia de las categorías marcadas por el tesauro es muy desigual en cada Grado. De las 156 citas localizadas en el Grado en Ciencias Ambientales a las 10 del Grado en Matemáticas o 6 en el caso de Psicología se evidencia una gran heterogeneidad. En este sentido, la mayoría de las memorias estudiadas presentan una posición intermedia con un número de citas variable tal como se observa en el Gráfico 1.

Destacan, con una presencia elevada de citas, los Grados de Ciencias Ambientales, Educación Social y Sociología (Gráfico 1). Sin embargo, son escasas en Ciencia Política, Psicología o Economía, especialmente significativo considerando que el concepto de sostenibilidad se nutre de una importante base económica y psicosocial.

Se observa una tendencia en todos los grados a presentar un mayor número de citas de la familia de categorías sociocultural. Realizando una revisión por Facultades (Gráfico 2), encontramos que en el caso de la Facultad de Ciencias, que cuenta con los grados en Matemáticas, Física, Química y Ciencias Ambientales, la balanza se inclina por las categorías relacionadas con el medio natural y la perspectiva económica, sin duda por las codificaciones del Grado en Ciencias Ambientales. La Facultad de Ciencias Económicas y Empresariales, desde donde se imparten los Grados en Economía, Administración y Dirección de Empresas y Turismo, presenta menos diferencias entre las distintas categorías y consideramos que es el Grado en Turismo el que favorece este equilibrio (ver Gráfico 1). 
GRÁFICO 1

NÚMERO DE CITAS POR CADA GRADO ${ }^{4}$

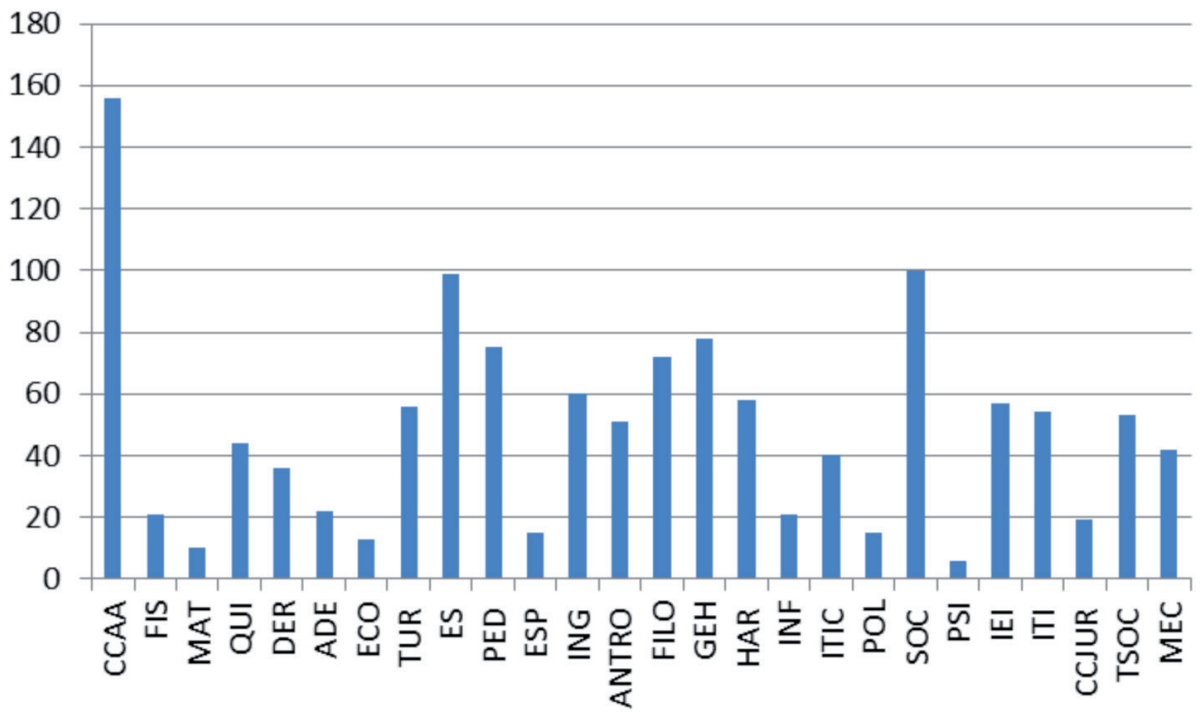

Respecto al análisis de citas por categorías, tal como ya se ha comentado, se observa una modesta presencia de menciones explícitas a la sostenibilidad (40 citas) y una mayor codificación de los aspectos socioculturales (758 citas). Estos últimos tienen una elevada y heterogénea presencia, especialmente las variables asociadas a la necesidad de respetar la diversidad y multiculturalidad, paz y seguridad humana (DIVCUL), el acceso a las nuevas tecnologías (TIC), apoyar la responsabilidad ética, principios éticos, valores (ETICN) y valorar el impacto ambiental y social de las actividades económicas (IMPCT), como puede apreciarse en el Gráfico 3.

4. Abreviaturas usadas en el nombre de los Grados: CCAA Grado en Ciencias Ambientales; FIS Grado en Física; MAT Grado en matemáticas; QUI Grado en Química; DER Grado en Derecho; ADE Grado en Administración y Dirección de Empresas; ECO Grado en Economía; TUR Grado en Turismo; ES Grado en Educación Social; PED Grado en Pedagogía; ESP Grado en Lenguas y Literatura Españolas; ING Grado en Estudios Ingleses: Lengua, Literatura y Cultura; ANTRO Grado en Antropología Social y Cultural; FILO Grado en Filosofía; GEH Grado en Geografía e Historia; HAR Grado en Historia del Arte; INF Grado en Ingeniería Informática; ITIC Grado en Tecnologías Industriales; POL Grado en Ciencia Política y de la Administración; soc Grado en Sociología; PSI Grado en Psicología, IEI Grado en Ingeniería Electrónica Industrial y Automática; iTi Grado en Ingeniería en Tecnologías de la Información; ccJuR Grado en Ciencias Sociales y Jurídicas; TSOc Grado en Trabajo Social; MEC Grado en Ingeniería Mecánica. 


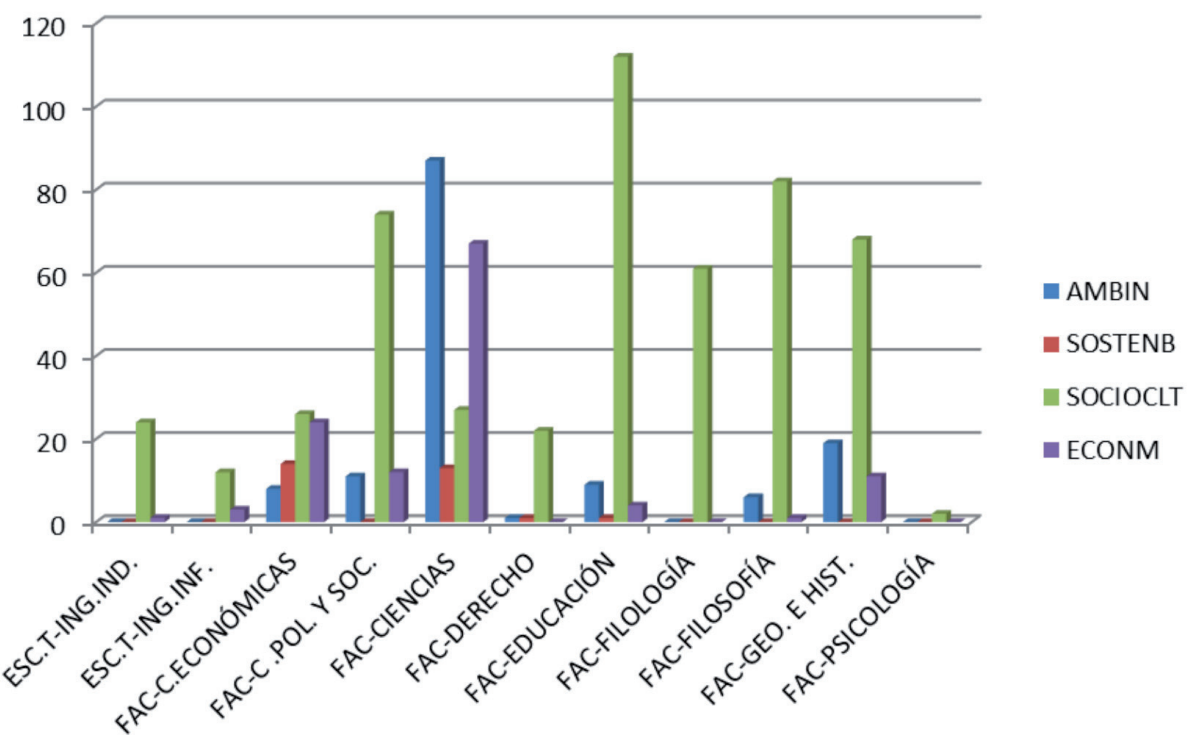

En contraposición los aspectos económicos (184 citas) y sobre todo los ambientales aparecen con menor representación (168 citas). En este sentido son notables algunas ausencias de citas como las referentes al urbanismo sostenible (URBN), la transformación rural (RURL) o la producción y el consumo responsable (PROCON) (Gráfico 3).

Las referencias a la sostenibilidad, en alguna de sus categorías, están presentes en los Grados y, aunque las codificaciones fluctúan notablemente de unos a otros, es esperanzador que ninguna titulación deje de tener en cuenta este enfoque, aunque las menciones sean escasas o estén muy focalizadas.

En este análisis se confirma un variado reparto de los códigos más repetidos: TIC (acceso a las nuevas tecnologías), DIVCul (necesidad de respetar la diversidad y multiculturalidad, paz y seguridad), ETICN (apoyar la responsabilidad ética, principios éticos, valores) e IMPC (valorar el impacto ambiental y social de las actividades económicas).

A pesar de haber encontrado un buen número de citas en las memorias y de que más del $60 \%$ de estos documentos presenten citas en 3 o más categorías, un análisis en profundidad de la codificación muestra una enorme desigualdad en el tratamiento de la sostenibilidad en los distintos Grados y una consistencia muy baja a la hora de presentar los Títulos como proyectos que contribuyen a formar profesionales con esta perspectiva. La mayor parte de ellas incluyen, ya en la definición del Título, una defensa del carácter necesario del mismo en función de la 
competitividad de los egresados en el mercado laboral, sin hacer alusión, por ejemplo, al contexto de crisis global y sistémica en la que van a desarrollar su trabajo.

GRÁFICO 3

NÚMERO DE CITAS POR VARIABLE DEL TESAURO

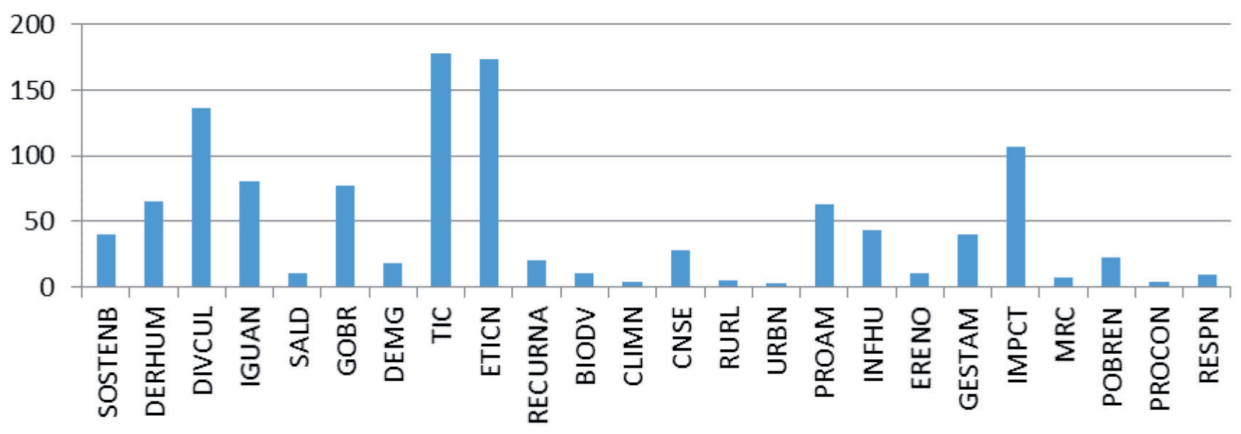

Las conclusiones a las que se podría dar la interpretación de todos estos datos han sido matizadas con la visión transversal de cada Grado comprobando la presencia efectiva de las categorías desde la definición del Título hasta las materias y los resultados de aprendizaje, como haremos en el siguiente apartado.

\subsection{Integración de la sostenibilidad en los elementos curriculares de los planes de estudio}

\subsubsection{La sostenibilidad en la descripción y los objetivos de los Títulos}

Una relación directa efectiva, que tenga en consideración la sostenibilidad como un aspecto a desarrollar en el diseño del Grado y por tanto una dimensión en la que formar a los estudiantes, debería estar presente en los epígrafes generales de los Grados, dedicados a presentar el Título y los profesionales que quieren formar (Justificación) o bien en otro apartado donde se fijen las metas que persigue la titulación (Objetivos). En este sentido, encontramos un número significativamente bajo de referencias explícitas al desarrollo sostenible.

- En el apartado de descripción del Título, lo encontramos en la Memoria del Grado en Química, que lo menciona en relación a un campo de actividad de los profesionales que va a formar: «Investigación, desarrollo, producción, transformación y control de la explotación industrial racional y sostenible de los recursos naturales» (p. 5). Se trata de una mención que no abarca el Título completo ni la formación integral de todos los estudiantes 
y que, además, parece tener una inclinación eminentemente centrada en el medio natural.

- Por lo que respecta a los objetivos la codificación tampoco es numerosa. Los encontramos en la Memoria del Grado en Ciencias Ambientales, se plantea como uno de los objetivos «formar a profesionales con una orientación específica [...] bajo la perspectiva de la sostenibilidad" (p. 14). Por su parte el Grado en Turismo señala «el egresado adquirirá habilidades que le permitan ser capaz de liderar el desarrollo de proyectos, así como de adaptarse eficazmente a un entorno de rápida evolución en un sector turístico actualmente caracterizado por las exigencias de calidad, competitividad y sostenibilidad" (p. 11). Es de suponer que, aunque no se indica explícitamente, esas habilidades tendrán que ver con exigencias de la sostenibilidad.

\subsubsection{Competencias que contribuyen a un desarrollo sostenible}

Para el diseño de los Grados, la UNED facilitó a sus Facultades una serie de áreas competenciales que debían ser incluidas en todas sus titulaciones (IUED, s. f.). Son las siguientes: a) Gestión autónoma y autorregulada del trabajo, b) Gestión de los procesos de comunicación e información, c) Trabajo en equipo desarrollando distinto tipo de funciones o roles y d) Compromiso ético.

Estas áreas han sido desarrolladas en mayor o menor medida en cada Grado; cada una cuenta con una distinta proyección en las materias y resultados de aprendizaje como posteriormente veremos, pero esta directiva ha propiciado la homogeneidad de competencias genéricas que encontramos en los Grados analizados.

En la diversidad de los Títulos se traduce con una presencia moderada de competencias genéricas y específicas relacionadas con la sostenibilidad, cada Grado cuenta con un número variable, fluctuando entre 1 y 4 competencias genéricas. 
GRÁFICO 4

NÚMERO DE CITAS ASOCIADAS A COMPETENCIAS GENÉRICAS (CG) Y ESPECÍFICAS (CE) POR GRADO

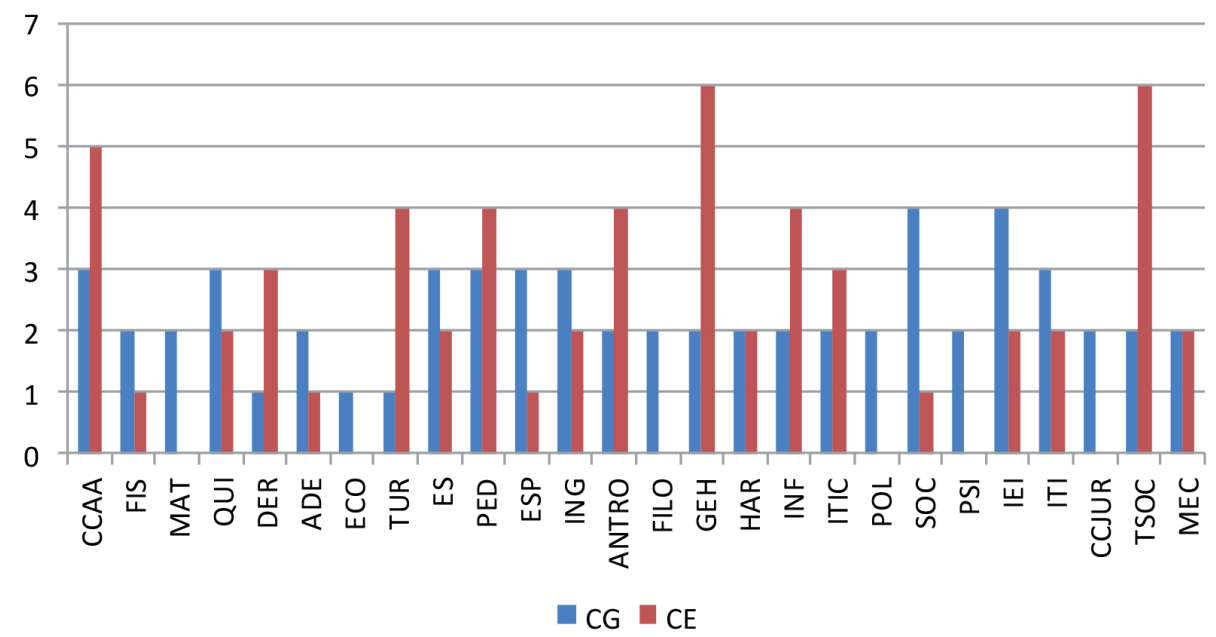

En los documentos destacan tres subcategorías: la primera de ellas, la relativa al acceso a la TIC (este elemento es necesario valorarlo en el contexto propio de la UNED); la segunda, vinculada a la ética y los valores (ETIC), y, finalmente, aquellas que hacen la mencionada referencia explícita a lo establecido en el R. D. 1393/2007. Esta normativa justifica la presencia de los códigos referidos, por un lado, a las cuestiones relativas a los Derechos Humanos (DERHUM), muy relacionadas con la diversidad cultural (DIVCULT), así como con la igualdad y las cuestiones de género (IGUAN). En estos casos, un estudio del significado de las citas en su contexto señala, sin embargo, una vinculación muy débil con la temática de la sostenibilidad.

Por lo que respecta a las competencias específicas, no todos los Grados presentan relaciones explícitas con alguno de los ámbitos de la sostenibilidad del tesauro. Es remarcable que ni siquiera los Grados con un mayor número de competencias específicas relacionadas con la sostenibilidad hagan explícita esta relación en la presentación del Grado y/o los objetivos. Se trata de los Grados en Geografía e Historia y Trabajo Social, que tampoco son los que cuentan con un mayor número de codificaciones si consideramos las Memorias en su conjunto.

La presencia de competencias para la sostenibilidad es muy desigual entre los distintos Grados no solo por la cantidad de citas relacionadas con las competencias, ,sino por la presencia de las distintas temáticas en ella. Ciertamente, como se observa en el Gráfico 5, destacan los ámbitos más presentes en las competencias genéricas. Igualmente, se evidencia una mayor representación de citas sobre competencias asociadas a familias de carácter sociocultural y en menor medida a la familia de aspectos económicos o ambientales. En este sentido, destaca la categoría de la Gobernanza 
(GOBR), relacionada en el tesauro con la democratización social: transparencia, debates libres, libertad de opinión, participación ciudadana, muy presente en los Grados de las Facultades de Ciencias Políticas y Sociología, así como Derecho.

\section{GRÁFICO 5}

PRESENCIA DE CITAS POR CATEGORÍAS DEL TESAURO ASOCIADAS A COMPETENCIAS

GENÉRICAS Y ESPECÍFICAS.

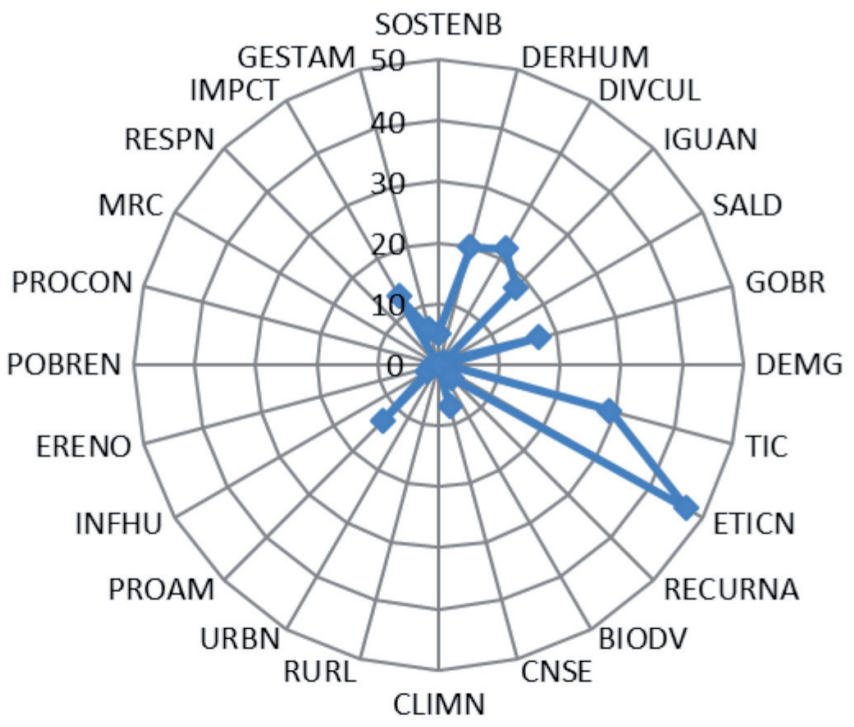

\subsection{Visión transversal de las memorias}

Los resultados del estudio permiten llamar la atención sobre la necesaria coherencia que debería estar presente en el diseño de los Grados entre lo expresado en la descripción del Título y, por otro lado, en la definición de las competencias y su concreción en resultados de aprendizaje.

La doble codificación, semántica y contextual, nos ha facilitado hacer un seguimiento transversal de las menciones a la sostenibilidad en función del lugar y de la forma que adquieren. La relación entre la presencia de las codificaciones en cada uno de los bloques considerados (objetivos, competencias, resultados de aprendizaje) es muy desigual y presenta unos porcentajes diferentes en cada Grado5

5. Para facilitar la comparación, en el Gráfico 6 hemos situado los valores absolutos de citas en cada titulación en la parte superior. En la parte inferior se presentan los porcentajes de citas en cada apartado. 
(Gráfico 6). El desequilibrio es más que evidente en el Grado en Psicología, donde las 2 competencias relacionadas con la sostenibilidad (prácticamente inapreciables en el gráfico) no tienen reflejo como resultados de aprendizaje, o en el de Trabajo Social.

Encontramos distintos Grados que cuentan con el mismo número de competencias que de resultados de aprendizaje. En el punto opuesto podemos situar, por ejemplo, el Grado en Ciencias Ambientales, que no solo tiene un buen número de competencias codificadas, sino que además hace un prolijo desarrollo de las mismas en resultados de aprendizaje o el caso del Grado en Ingeniería Mecánica que cuenta con 2 competencias específicas codificadas y se traducen en 13 resultados de aprendizaje.

GRÁFICO 6

DISTRIBUCIÓN DE CITAS POR APARTADOS DE LAS MEMORIAS
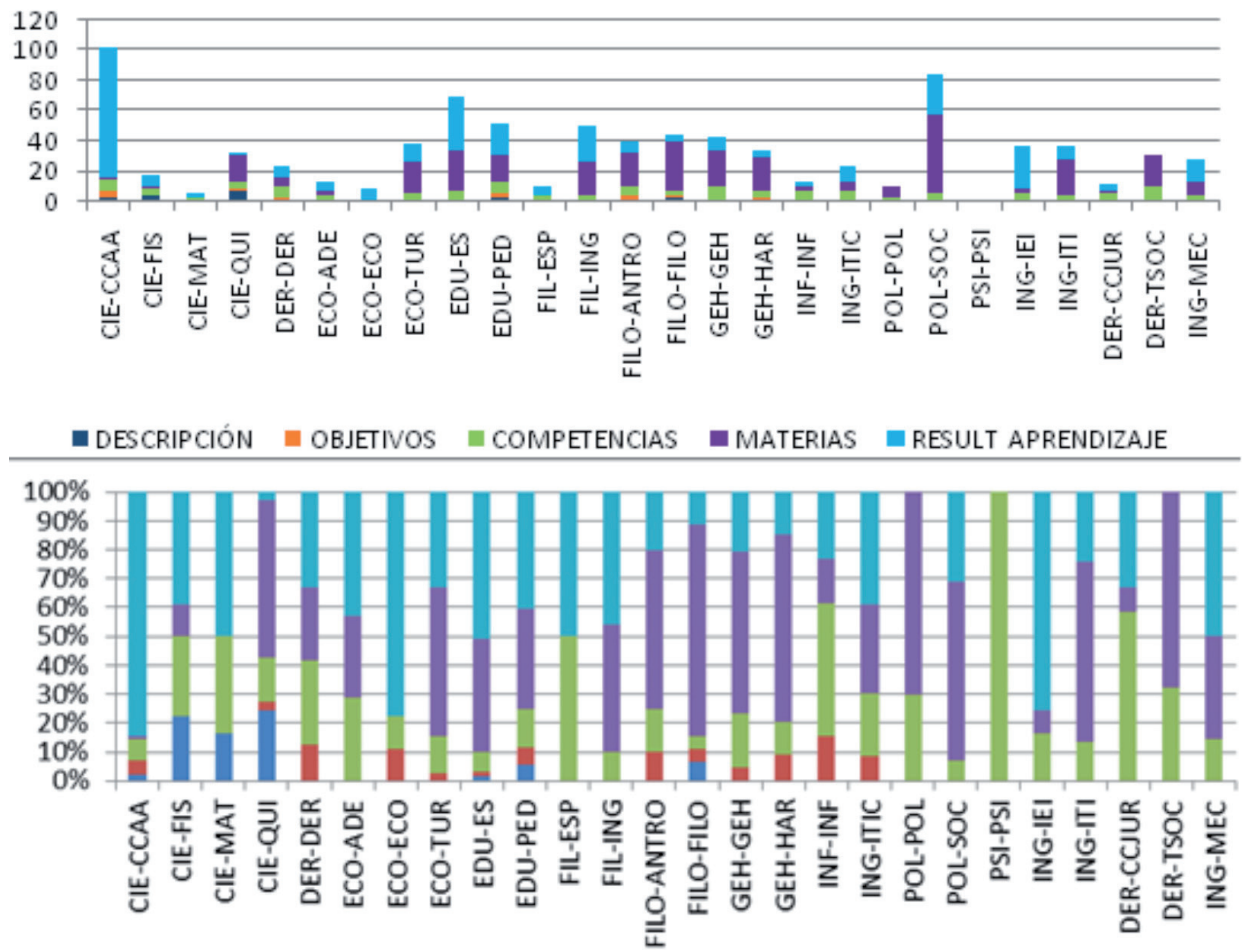

=DESCRIPCIÓN $=$ OBJETIVOS $=$ COMPETENCIAS $=$ MATERIAS $=$ RESULT APRENDIZAJE

No se trata de una cuestión baladí, ya que como vemos existen Grados en los que la proporción entre competencias y resultados de aprendizaje es inferior, 
similar o ligeramente superior. La ANECA adopta la definición del Marco de Cualificaciones del Espacio Europeo de Educación Superior (A Framework for Qualifications of the European Higher Education Area) para los resultados de aprendizaje: «Son declaraciones de lo que se espera que un estudiante conozca, comprenda y/o sea capaz de hacer al final de un periodo de aprendizaje» $(2013,16)$. Sin embargo, deja muy abierta la cuestión de cuántos resultados de aprendizaje son necesarios. "La clave es incluir el número de resultados del aprendizaje que permita a los estudiantes el logro de los objetivos del programa o materia. Un número entre 5 y 10 se considera bastante habitual. En ningún caso se recomienda sobrepasar el límite superior de 10 resultados de aprendizaje» (ANECA, 2013, 34). Aunque sí indica expresamente que «una de las características más importantes de los resultados del aprendizaje es que sean evaluables» (ANECA, 2013, 25). El hecho de que no sea evidente la correspondencia entre competencias y resultados de aprendizaje implica a su vez que se diluye su presencia en la evaluación y, por tanto, se disipa la posibilidad de recogida de evidencias sobre su aprendizaje. Esto, inevitablemente, pone en entredicho la efectiva formación de los estudiantes en sostenibilidad a pesar de encontrar competencias que sí la recojan.

GRÁFICO 7

COMPARATIVA DE LA PRESENCIA DE CITAS EN LAS COMPETENCIAS

Y EN LOS RESULTADOS DE APRENDIZAJE

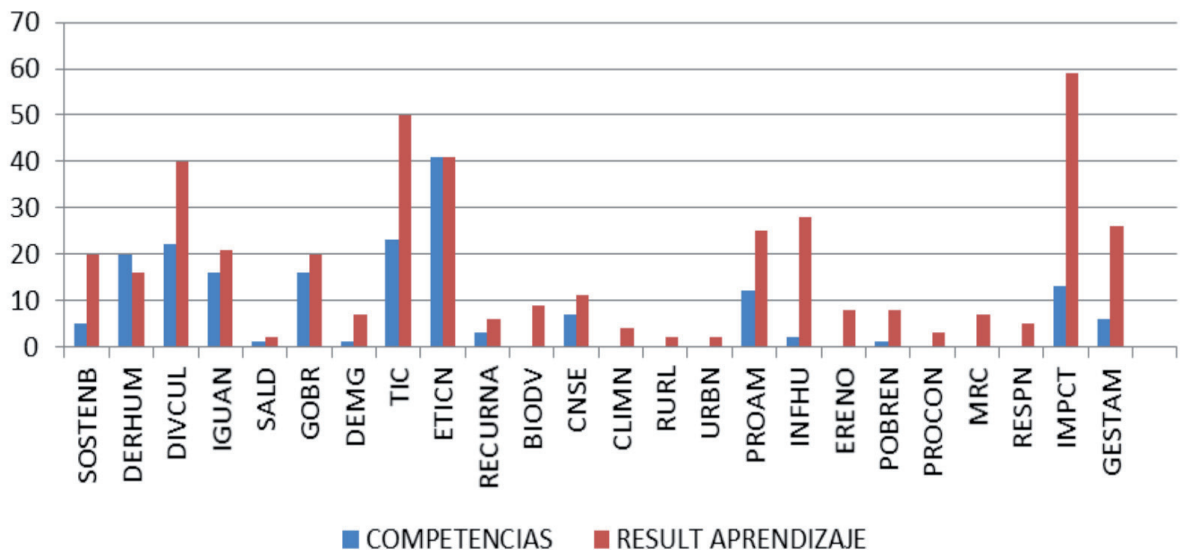

En cualquier caso consideramos que un número alto de resultados de aprendizaje ayudaría a introducir elementos de sostenibilidad aun cuando no se encuentren competencias que explícitamente los presenten. Cuestión especialmente significativa en el caso de IMPCT (valorar el impacto ambiental y social de las actividades económicas) o de INFHU (influencia e intervención humana en el medio ambiente). Caso aparte ha constituido en este estudio la competencia ética (ETICN), que tiene 
MARÍA JOSÉ BAUTISTA-CERRO RUIZ Y MARÍA JOSÉ DÍAZ GONZÁLEZ

LA SOSTENIBILIDAD EN LOS GRADOS UNIVERSITARIOS: PRESENCIA Y COHERENCIA

un número de citas idéntico, pero cuyo análisis en profundidad resulta muy desalentador pues tiende a desaparecer o a tratarse únicamente como deontología profesional.

\section{DISCUSIÓN Y CONCLUSIONES}

Tal y como se ha puesto de manifiesto, un análisis en profundidad de las memorias de los Grados muestra una enorme desigualdad en la presencia y en el tratamiento de la sostenibilidad en cada una de ellas. Además de una consistencia muy baja a la hora de presentar los Títulos como proyectos que contribuyen a formar profesionales que ayuden a orientar la transición de nuestras sociedades hacia la sostenibilidad. Entendemos que este punto debería estar presente en la definición y descripción del Título, así como en los objetivos planteados en el mismo, ya que constituyen los pilares para desarrollar las competencias, las materias y las asignaturas de cada Grado.

Por otro lado, es común encontrar, ya en la definición del Título, una defensa del carácter necesario del mismo en función de la competitividad de los egresados para incorporarse al mercado laboral, sin hacer alusión, por ejemplo, al contexto de crisis global y sistémica en la que van a desarrollar su trabajo. La empleabilidad, presente en las memorias, tiene un sentido individual, tal y como mencionábamos al principio, de manera que toda la responsabilidad de encontrar y mantener un trabajo recae sobre el propio individuo y sobre las instituciones educativas que se ocupan de su formación (Bautista-Cerro, 2014) y no en el sentido amplio que plantea Yorke (2004) como un conjunto de logros, habilidades, conocimientos y atributos personales que aumentan la probabilidad de los graduados de encontrar un empleo y de tener éxito en sus puestos de trabajo en beneficio propio y también de la economía y la sociedad en su conjunto. Este beneficio es multidimensional y no puede dejar fuera a la sostenibilidad como elemento vertebrador de justicia social, así como de la integridad ecológica y la viabilidad económica.

Estas cuestiones hay que valorarlas atendiendo al momento histórico en el que se diseñaron los Títulos. No podemos pasar por alto que en las recomendaciones de ANECA para el diseño de Títulos se presentaba como criterio para la evaluación positiva el interés profesional del Título. Además, los Grados también se diseñaron en un momento en el que la crisis comenzaba a hacer su aparición con tasas de desempleo en aumento y una clara precarización del trabajo.

Por otro lado, se detecta una gran diferencia en la presencia de los temas relativos a la sostenibilidad en función de las citas por familias. Destaca significativamente la presencia de referencias de la familia sociocultural, como hemos visto debido al peso que presentan las competencias genéricas, además de aglutinar temáticas muy amplias que suelen estar presentes de una u otra manera en Grados del área de Humanidades y Ciencias Sociales (Derechos Humanos, diversidad cultural, género, etc.). De ahí que encontremos un gran desequilibrio al analizar estas memorias (como se refleja en el Gráfico 2). Las temáticas de las 
familias ambiental (AMBIN) o económica (ECONM) mantienen una presencia, en general, muy limitada.

Una causa de esta concentración en torno a las temáticas tratadas en las titulaciones de estas áreas podría tener relación con la reducción que experimentaron la mayor parte de los programas al pasar de Licenciaturas, de 5 años, a Grados, de 4 años, cambio que supuso una reducción de estos últimos obligando a las Facultades a focalizarse en lo que se consideraba sustantivo de cada uno. Entendemos que esto dificulta no solo avanzar en el desarrollo de competencias en sostenibilidad, sino en adquirir una visión interdisciplinar respecto de los conocimientos a lo largo de cada Grado.

Igualmente, en los resultados obtenidos destaca la descompensación entre el número de citas presentes entre los apartados de competencias y resultados de aprendizaje. Entendemos que esto no tendría que ser así. Si seguimos la literatura generada por ANECA, "se considerará que los resultados del aprendizaje son concreciones de las competencias para un determinado nivel y que son el resultado global del proceso de enseñanza-aprendizaje» (2013, 22). Por tanto, una competencia debería concretarse en resultados de aprendizaje que se definen en distintas acciones expresadas con diferentes verbos «dependiendo de la complejidad de la materia, el grado de profundización requerido o el nivel de autonomía exigido para el estudiante» (ANECA, 2013, 25). Siendo así, la proporción de resultados de aprendizaje relacionados con algún aspecto de la sostenibilidad debería ser muy superior a la de las competencias. Sin embargo, en los resultados no es así, por lo que entendemos que se trata de un elemento al que debe prestarse atención y elaborar líneas de mejora.

La mención expresa al desarrollo de temas relativos a la sostenibilidad en el ya comentado Real Decreto 1393/2007 en el que están basados los Grados no ha asegurado una presencia abundante de estos temas. Uno de los motivos podría ser que la mención se produce en el preámbulo, que, aun considerándose una fuente interpretativa de la norma, "carecen de valor normativo» según el Tribunal Constitucional (en fallo del 4 de octubre de 1990). Por lo tanto, estamos hablando más de una expresión de buenas intenciones o buenos deseos que de una cuestión que se considere sustantiva y que será objeto de revisión y/o evaluación.

Este hecho es determinante ya que sitúa todos los hallazgos de las memorias, por pocos que nos puedan parecer, en el ámbito de la voluntad de los equipos de diseño de las instituciones o bien de los equipos docentes. Pone de manifiesto que en las universidades este compromiso se va abriendo paso con la ayuda de profesores que de manera individual lo incluyen en sus asignaturas, y también de gestores y decisores (académicos en su mayor parte) que introdujeron elementos de sostenibilidad, en mayor o menor medida, en el diseño de los Grados. Sin duda, una vez superados los primeros años de trabajo, puede ser el momento para profundizar en esta vertiente desde una doble dirección. De abajo a arriba, desde los equipos docentes comprometidos en la sostenibilización curricular y, por otra, desde las agencias de evaluación de la calidad de las universidades (ANECA y 
agencias regionales), incluyendo, entre los criterios de valoración de los Títulos, la formación en sostenibilidad.

Queda mucho camino por recorrer desde la universidad. Una vez que se cuenta con el mapa de situación y se han detectado las posibilidades de mejora en cuestión de sostenibilización curricular, es necesario hacer partícipe a la comunidad universitaria de la importancia de este reto. El trabajo con los docentes y con los órganos gestores de la universidad son cuestiones que deben desarrollarse de manera paralela si se quiere avanzar a un paso adecuado. No hacerlo significa hurtar a nuestros estudiantes de una vertiente cada vez más imprescindible para su desarrollo personal y laboral y de otra a la sociedad de profesionales capaces de responder al desafío que la problemática ambiental presenta cada día.

\section{AGRADECIMIENTOS}

Este artículo recoge resultados del proyecto de investigación «La sostenibilidad en los Grados de la UNED: análisis y propuestas», UNED 2013-024-UNED-PROY, Convocatoria Proyectos Jóvenes Investigadores. Además de las autoras del texto, son miembros del equipo de investigación las profesoras María Novo y María de los Ángeles Murga-Menoyo.

\section{REFERENCIAS BIBLIOGRÁFICAS}

Albareda-Tiana, S. y GonZalvo-Cirac, M. (2013) Competencias genéricas en sostenibilidad en la educación superior. Revisión y compilación. Revista de Comunicación de la SEECI, año Xv (32), 141-159. Consultado el 5 de diciembre de 2016. http://dx.doi. org/10.15198/seeci.2013.32.141-159.

ANECA (2013) Guía de apoyo para la redacción, puesta en práctica y evaluación de los resultados de aprendizaje. Consultado el 5 de diciembre de 2016. https://goo.gl/DpnGNE.

Aznar Mínguet, P. y Ull, M. A. (2013) La responsabilidad por un mundo sostenible. Propuestas educativas para padres y profesores. Bilbao, Desclée De Brouwer.

Aznar Mínguet, P.; Ull, M. A.; MarTínez-Agut, M. P. y Piñero, A. (2013) El Tesauro de Sostenibilidad. Universidad de Valencia. Consultado el 5 de diciembre de 2016. https:// goo.gl/GBvBy1.

Aznar Mínguet, P.; Ull, M. A.; Piñero, A. y Martínez-Agut, M. P. (2016) Competencies for Sustainability in the Curricula of all new Degrees from the University of Valencia (Spain), en Barth, M.; Michelsen, G.; Rieckmann, M. y Thomas, I. (eds.) Handbook of Higher Education for Sustainable Development. New York, Routledge.

BARAÑANo, M. (2012) La responsabilidad social como misión en las universidades españolas y su contribución al desarrollo sostenible. Diagnóstico y buenas prácticas. Consultado el 5 de diciembre de 2016. http://138.4.83.162/mec/ayudas/repositorio/201211302135 10INFORME_RSU_2.pdf.

Barrón, A.; NAVARrete A. y FerRer-Balas, D. (2010) Sostenibilización curricular en las universidades españolas. ¿Ha llegado la hora de actuar? Revista Eureka sobre Enseñanza y Divulgación de las Ciencias, 7 (Extra). 
Barth, B.; Godemann, J.; Rieckmann, M. y Stoltenberg, U. (2007) Developing key competencies for sustainable development in higher education. International Journal of Sustainability in Higher Education, 8:4, 416-430.

Bautista-Cerro, M. J. (2014) (Re)construcción del concepto de empleabilidad desde la universidad. La sostenibilización curricular como elemento clave. Procedia-Social and Behavioral Sciences, 139, 536-542.

Boltansky, L. y Chiapello, E. (2002) El Nuevo espiritu del capitalismo. Madrid, Akal.

CADEP-CRUE (2011a) Evaluación de las políticas universitarias de sostenibilidad como facilitadoras para el desarrollo de los campus de excelencia internacional. Informe Final del Grupo de evaluación de la sostenibilidad. Consultado el 5 de diciembre de 2016. https://goo.gl/OBnsbq.

CADEP-CRUE (2011b) Directrices para la introducción de la Sostenibilidad en el Currículum. Consultado el 5 de diciembre de 2016. https://goo.gl/WX8zc6.

COMISIÓN EUROPEA (2016) Next steps for a sustainable European future European action for sustainability. $\operatorname{COM(2016)} 739$ final. Consultado el 10 de diciembre de 2016. https:// goo.gl/aFF4DQ.

DESA (2016) World Economic and Social Survey 2016: Climate Change Resilience - An Opportunity for Reducing Inequalities. Un. Consultado el 5 de diciembre de 2016. http://www.un-ilibrary.org/economic-and-social-development/ world-economic-and-social-survey-wess_69d42e13-en.

DE HAAN, G. (2010) The development of ESD-related competencies in supportive institutional frameworks. International Review of Education, 56, 315-328.

De Kraker, J.; Cörvers, R.; Ivens, W.; Lansu, A. y Van Dam-Mieras, R. (2007) Crossing boundaries - competence-bases learning for sustainable development in a virtual mobility setting. Consultado el 5 de diciembre de 2016. https://goo.gl/Sgq2b.

García-GutiérReZ, J. (2014) ¿Por qué lo llaman educación cuando quieren decir... empleabilidad? A propósito del concepto de utilidad en educación. Procedia - Social And Behavioral Science, 139, 102-109.

IPCC (2013) Climate Change 2013: The Physical Science Basis. Contribution of Working Group I to the Fifth Assessment Report of the Intergovernmental Panel on Climate Change. Cambridge, Cambridge University Press.

IUED (s. f.) Propuesta del mapa de competencias genéricas de la UNED. Consultado el 5 de diciembre de 2016. https://goo.gl/KZuV9l.

JunYENT, M. y GELI, A. M. (2008) Education for Sustainability in University Studies: A Model for Reorienting the Curriculum. British Educational Research Journal, 34 (6), 763-782.

LEY Orgánica 4/2007, de 12 de abril, por la que se modifica la Ley Orgánica 6/2001, de 21 de diciembre, de Universidades.

Martín del Peso, M.; Rabadán, A. B. y Hernández, J. (2013) Desajustes entre formación y empleo en el ámbito de las enseñanzas técnicas universitarias: la visión de los empleadores de la Comunidad de Madrid. Revista de Educación, 360, 244-267.

Medina Rubio, R. (2005) Misiones y funciones de la Universidad en el espacio europeo de educación superior. Revista Española de Pedagogía, 230, 17-42.

Ministerio de CienCIa e InNOVACIÓn (s/f) Estrategia Universidad 2015. Universidades para el progreso, el bienestar y la competitividad. Consultado el 5 de diciembre de 2016. http:// www.mecd.gob.es/dms-static/a8c5f36e-f467-4e87-b749-3529cc3b856b/2011-estrategiauniversidad-2015-pdf.pdf. 
Ministerio de EduCACIÓN (2011) Estrategia Universidad 2015. Contribución de las universidades al progreso socioeconómico español 2010-2015. Consultado el 5 de diciembre de 2016. https://sede.educacion.gob.es/publiventa/\%20detalle.action?cod=14246.

Murga-Menoyo, M. Á. (2014) Learning for a Sustainable Economy: Teaching of Green Competencies in the University. Sustainability, 6, 2974-2992.

Murga-Menoyo, M. ${ }^{a}$ Á. (2015) Competencias para el desarrollo sostenible: las capacidades, actitudes y valores meta de la educación en el marco de la Agenda global post-2015. Foro de Educación, 13 (19), 55-83.

Novo, M. (2009) La educación ambiental: una genuina educación para el desarrollo sostenible. Revista de Educación, número extraordinario, 195-217.

ONu (2015) Proyecto de documento final de la cumbre de las Naciones Unidas para la aprobación de la agenda para el desarrollo después de 2015, A/69/L.85 (12 de agosto de 2015). Consultado el 5 de diciembre de 2016. http://www.un.org/es/comun/ docs/?symbol=A/69/L.85.

ONu (2016) Objetivos de Desarrollo Sostenible. Consultado el 5 de diciembre de 2016. http:// www.un.org/sustainabledevelopment/es/objetivos-de-desarrollo-sostenible/.

PNUMA (2011) Hacia una economía verde: Guía para el desarrollo sostenible y la erradicación de la pobreza - Sintesis para los encargados de la formulación de políticas. Consultado el 5 de diciembre de 2016. www.unep.org/greeneconomy.

PRATS, F. (2016) La gran encrucijada. Sobre la crisis ecosocial y el cambio de ciclo bistórico. Madrid, Libros en Acción. Consultado el 5 de diciembre de 2016. http://blogs.fuhem.es/ forotransiciones/wp-content/uploads/sites/51/2016/07/Libro_La_gran_encrucijada.pdf.

REAl DeCRETO 1393/2007, de 29 de octubre, por el que se establece la ordenación de las enseñanzas universitarias oficiales.

RieCKMANN, M. (2012) Future-oriented higher education: Which key competencies should be fostered through university teaching and learning? Futures, 44 (2), 127-135.

RODRíGuez EsPinAR, S. et al. (2010) Sobre la empleabilidad de los graduados universitarios en Catalunya: Del diagnóstico a la acción. Revista de Educación, 351, 107-137.

Sipos, Y.; BAtTISTI, B. y GRIMM, K. (2008) Achieving transformative sustainability learning: engaging head, hands and heart. International Journal of Sustainability in Higher Education, 9:1, 68-86.

Thijssen, J.; VAn Der Heijden, B. y Rocco, T. (2008) Toward the employability link model: current employment transition for future employment perspectives. Human Resource Development Review, 7, 165-183.

Tilbury, D. (2011) Education for Sustainable Development: An Expert Review of Processes and Learning. París, unESCO. Consultado el 5 de diciembre de 2016. http://unesdoc. unesco.org/images/0019/001914/191442e.pdf.

Ull, M. ${ }^{a}$ A.; Martínez Agut, M. ${ }^{a}$ P.; Piñero, A. y Aznar Minguet, P. (2010) Análisis de la introducción de la sostenibilidad en la enseñanza superior en Europa: compromisos institucionales y propuestas curriculares. Revista Eureka, 7, 413-432.

UNESCO (2015a) Replantear la educación. ¿Hacia un bien común mundial? París, Ediciones Unesco. Consultado el 5 de diciembre de 2016. http://unesdoc.unesco.org/ images/0023/002326/232697s.pdf.

unESCO (2015b) Declaración de Icheon. Foro Mundial sobre la Educación. Consultado el 5 de diciembre de 2016. https://es.unesco.org/world-education-forum-2015/about-forum/ declaracion-de-incheon.

UE4SD (2015) Leading Practice Publication: Professional development of university educators on Education for Sustainable Development in European countries, en KAPITULČINOVÁ, 
D.; Dlouhá, J.; Ryan, A.; DlouhÝ, J.; Barton, A.; Mader, M.; Tilbury, D.; Mula, I.; Benayas, J.; Alba, D.; Mader, C.; Michelsen, G. y Vintar Mally, K. (eds.) Praga, Charles University in Prague.

Unión Europea (s. f.) Estrategia en favor del Desarrollo Sostenible. Consultado del 5 de diciembre de 2016. http://eur-lex.europa.eu/legal-content/ES/TXT/?uri=URISERV:128117.

UNECE (2011) Learning for the future: Competences in Education for Sustainable Development, ECE/CEP/AC.13/2011/6. Consultado el 5 de diciembre de 2016. https://www. unece.org/fileadmin/DAM/env/esd/6thMeetSC/Learning\%20for\%20the\%20Future_\%20 Competences\%20for\%20Educators\%20in\%20ESD/ECE_CEP_AC13_2011_6\%20COMPETENCES\%20EN.pdf.

Wiek, A.; Withycombe, L. y Redman, C. L. (2011) Key competencies in sustainability: a reference framework for academic program development. Sustainability Science, 6 (2), 203-218.

YORKE, M. (2004) Employability in higher education: what it is-what it is not. York, Higher Education Academy. Consultado el 5 de diciembre de 2016. http://www.employability. ed.ac.uk/documents/Staff/HEA-Employability_in_HE(Is,IsNot).pdf. 